\title{
Expert system application for reactive power compensation in isolated electric power systems
}

\author{
A. K. Kirgizov ${ }^{1}$, S. A. Dmitriev², M. Kh. Safaraliev ${ }^{3}$, D. A. Pavlyuchenko ${ }^{4}$, A. H. Ghulomzoda ${ }^{5}$, \\ J. S. Ahyoev ${ }^{6}$ \\ ${ }^{1,6}$ Department of Electric Power Stations, Tajik Technical University named after academic M. S. Osimi, Tajikistan \\ ${ }^{2,3}$ Department of Automated Electrical Systems, Ural Federal University Ekaterinburg, Russian Federation \\ ${ }^{4}$ Department of Power Supply Systems, Novosibirsk State Technical University, Novosibirsk, Russian Federation \\ ${ }^{5}$ Department of Automated Electric Power Systems, Novosibirsk State Technical University, Novosibirsk,
} Russian Federation

\section{Article Info \\ Article history: \\ Received Jul 2, 2020 \\ Revised Oct 15, 2020 \\ Accepted Mar 5, 2021}

\section{Keywords:}

Experts

Fire-fly algorithm

Fuzzy logic

Fuzzy relationship matrix

Losses

Reactive power

Voltage

\begin{abstract}
Effective electricity use can be an option which enables to achieve significant economy while generating and transmitting of electricity. One of the most important things is to improve the electricity quality through reactive power correction up to optimum values. The current article presents the solution to compensate the reactive power in the distribution networks, in GornoBadakhshan Autonomous Oblast (GBAO) with the use of the advanced technologies based on the data collection within real time. The article describes the methodology of fuzzy logic application and bio-heuristic algorithms for the suggested solution effectiveness to be determined. Fuzzy logic application to specify the node priority for compensating devices based on the linguistic matrix power loss and voltage gives the possibility to the expert to take appropriate solutions for compensating devices installation location to be determined. The appropriate (correct) determination of the compensating devices installation location in the electric power system ensures the effective regulation of the reactive power with the least economic costs. Optimization problems related to the active power loss minimization are solved as well as the cost minimization with compensating devices to ensure the values $\tan (\varphi)$ not exceeding 0.35 through reducing multi-objective problem to the single-objective one using linear convolution.
\end{abstract}

This is an open access article under the CC BY-SA license.

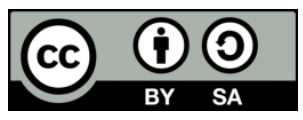

Corresponding Author:

D. A. Pavlyuchenko

Department of Power Supply Systems

Novosibirsk State Technical University

20, Karl Marx prospekt, Novosibirsk, 630073, Russian Federation

Email: pavlyuchenko@corp.nstu.ru

\section{INTRODUCTION}

One of the widely used mathematical devices is models based on the fuzzy logic to resolve current problems of safety evaluation, system rehabilitation and planning and mode operation control of electricity network today. The fuzzy logic field of application is broadened in the repair planning and electrical failures, load predicting and electrical failures detection. Traditional mathematical models are based on the knowledge containing set of rules defining corresponding actions for given system modes [1]-[3]. If the information is fuzzy, the expert systems cannot operate well with this data. Fuzzy expert system application allows improving the abovementioned traditional systems failures based on the knowledge and accurate data. 
A thematic review of the work on expert systems for reactive power compensation and bus voltage maintenance at consumers is presented in some publications. The work [4] considers the control of reactive power in distribution systems using advanced technologies. Based on the artificial intelligence method, some computation systems, such as expert systems, fuzzy systems, artificial neural networks, and hybrid systems for voltage control in distribution systems, have been considered. The work [5] presents an optimization of reactive power compensation and voltage regulation using an artificial immune algorithm for radial electrical networks. In the work [6] an optimization of the load voltage and reactive power in the power system using fuzzy logic is presented. The authors have proposed an original method of optimizing the reactive power flow, which leads to an improvement in the voltage level in the power system and a reduction in the loss of active power. The work [7] considers the use of fuzzy logic with a complete search for the arrangement of distributed generation in order to reduce losses and improve the voltage level. In the work [8] a filter with fuzzy logic and active power to compensate reactive power and eliminate harmonics is investigated. The invention relates to a three-phase shunting active filter with fuzzy logic for improving the electric power quality by compensating the reactive power and harmonic current required by a non-linear load. Fuzzy logic approach for coordination of reactive power in grid-connected wind power plants to increase stability of voltage in the installed mode is considered in [9]. The realization of fuzzy logic for controlling the reactive power in a communal system is presented in [10]. It is noted that the reactive power requirements calculated using the fuzzy logic approach are much lower than the traditional method, which is more economical and requires fewer capacitors or reactive compensation devices.

A new strategy for optimum reactive power compensation based on the mining algorithm and ant colony analyzed in [11]. The results show that the application of the new algorithm proposed in the work can increase the efficiency of the system and reduce losses, which is of great economic importance for voltage control. In [12], the application of the particle swarm optimization method to optimize reactive power is considered. The paper presents a new reactive power optimization algorithm using the Particle Swarm algorithm, the task of which is to minimize active power losses in the system. Optimization of reactive power based on hybrid particle processing is considered in [13]. The work uses the approach of two-phase optimization of hybrid particles in order to solve the problem of optimal distribution of reactive power in the network.

In this article to determine the location of the damage, network configuration as well as the load prediction, the membership function was successfully applied. To regulate the reactive power and to control the voltage level in the network as well as the adequate determining of compensating devices installation location the fuzzy logic can be applied.

\section{OBJECT STUDY DESCRIPTION}

The power sector in Tajikistan is managed by the open joint stock holding company (OJSHC) «BarqiTojik» being one of the state ownerships. There are all large power stations and regional networks owned by the enterprise and, correspondingly it controls the electricity generation, transmission and distribution throughout the entire territory of the country except GBAO. Since December 2002, the electricity grid shifted from BarkiTochik Company to the private-owned power utility "Pamir Energy" on the basis of the Concession Agreement for the period of 25 years and started operating in isolation, i.e. without any connection with the main country electricity grid.

Currently, "Pamir Energy" utility supplies electricity to 213000 customers in GBAO. The GBAO area makes $64000 \mathrm{~km}^{2}$ and consists of 8 districts. Throughout GBAO the power utility has on its balance sheet 11 hydro power plants (HPP) with total electrical power $43.5 \mathrm{MW}$ and located in different districts of the region. The total length of electric transmission lines (ETL) throughout GBAO makes $2.609 \mathrm{~km}$ (voltage 35/10/0.4 kV). Geographic location of electric power system (EPS) is given in Figure 1.

To date, the EPS, GBAO, is experiencing serious difficulties related not only to sustainable electricity deficit within winter period but to the low quality of electric power supplied to its customers. The root causes of the irregular GBAO EPS operation are as follows:

- Due to GBAO specific geographic locality, the electrical networks have radial circuit with a large electric ETLlength with voltage $35 \mathrm{KV}$ about $100 \mathrm{~km}$ resulting in profound voltage reduction at ETL endpoints;

- As power plants are of low power, the power network loss occurs while regulating the voltage at these power plants generators.

Thus, the relevance of the work is specified by the research conducted and solutions searched to reduce the risk of power failures and, also with the possibility of reactive power regulation using compensating devices optimal location as well as to meet the technical and economic requirements taking into account the current power plants capacity [1]-[3]. 


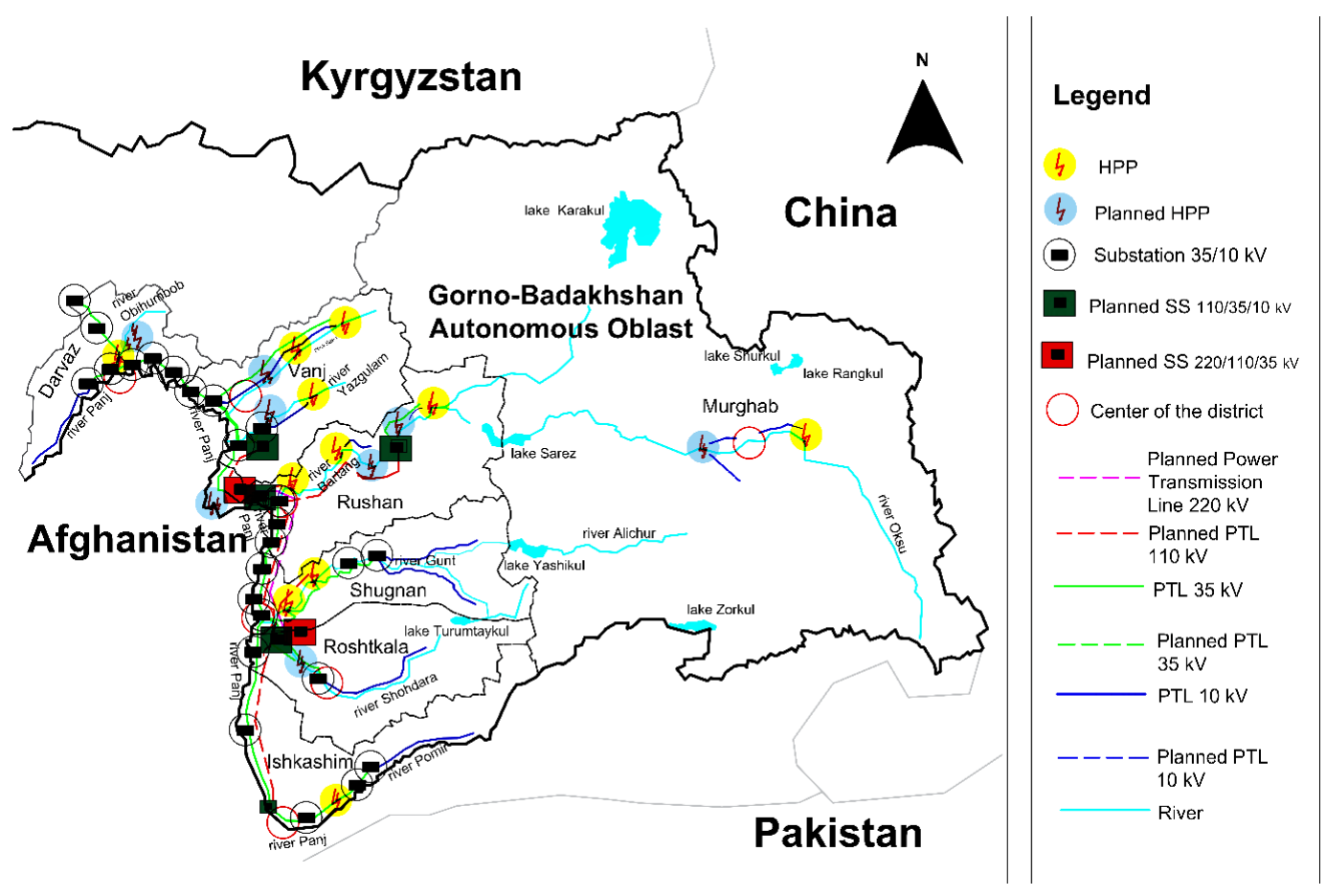

Figure 1. Map of EPS, GBAO, Tajikistan

\section{PROBLEM STATEMENT}

Medium and low voltage distribution networks represent the local electrical network systems basis not always connected with the depleted power system. The challenge for such networks and local power centers is the necessity of voltage level sustaining and active and reactive power loss reduction. The reactive power network mode optimization is achieved by two ways. The first way includes the need to determine the installation location and reactive power source location principles as compensating devices (CD) or static synchronous compensator (STATCOM). The second one assumes the installed reactive power optimization in the locations by using corresponding mathematical apparatus.

The compensating devices location selection methodology is developed and proposed in the present article. The methodology is based on the number of heuristic rules being simulated as a fuzzy membership function. Such rules allow defining the nodes of electrical network with high sensitivity index towards reactive power source installation. These nodes are selected as basic areas for $\mathrm{CD}$ locations. The article deals with swarm intelligence algorithms due to what the reactive power optimization is implemented in one of the nodes considered. Swarm optimization algorithms were proved themselves well in a global optimization problem solution [14]. A study of the relative characteristics of the firefly method was carried out. Due to the fuzzy set of fuzzy logic the swarm intelligence algorithms applicability is significantly widened in the optimization problems of the local electric networks modes with the reactive power, voltage, and power factor and active power loss.

\section{COMPENSATING DEVICES ALGORITHM SELECTION USING FUZZY LOGIC}

To determine the CDs location on the basis of fuzzy logic model it is necessary to specify the membership functions solutions classification per voltage levels in the nodes and power losses in the branches. The location of compensating devices (CD) installation is planned upon active power loss defining and voltage reducing in the electrical network. CDs installation in the nodes allows increasing the voltage level in this network. After calculations made in the nodes where the low voltage level occurs, the CDs are located and it is not recommended to install CDs at high voltage nodes. Linguistic terms such as high, medium and low power loss cannot be used for the rules formulation in their common, clear understanding. And with this understanding, the fuzzy model of fuzzy relationship can be set up to determine the appropriate location for CDs installation into power supply system or into electricity power distribution system [15]-[18]. Fuzzy set theory is based on some notions and definitions part of which is taken a priori and the other one is on convectional basis. One of the important things is a notion of linguistic variable and membership function. 
Fuzzy set is such a set being on some universal scale for which the set of pairs can be written down representing the membership relation of the element of the set to a fuzzy set. Number and properties selecting of fuzzy variables is referred to the author's art. Fuzzy variables quantity is determined by so called syntax of a linguistic variable and their pragmatic meaning-by semantic linguistic variable [19]-[23]. The second important component is a membership function. It is a sort of the description model (object-deputy) in a fuzzy world. This basic variable (for example-voltage and power loses) can have some shades of meaning, semantics which can be expressed by a membership function.

If the statement is a cause, the conclusion is a consequence. To determine the location of compensating devices installation in a certain node, the sets of numerous antecedents fuzzy rules are developed. Entry into the rules is a voltage level, a power and loss factor and exit (consequences) is a node suitability to locate CDs. The solution technique to install CDs in the specific node is carried out on the basis of accumulating rules in the fuzzy relationship matrix. Fuzzy linguistic variables of the voltage in the nodes are described by the following membership functions: low, below average, average, above average and high. The solution of the problem set is based on the suggested approach for the fragment of the electric power system distribution network in GBAO, given in Figure 2.

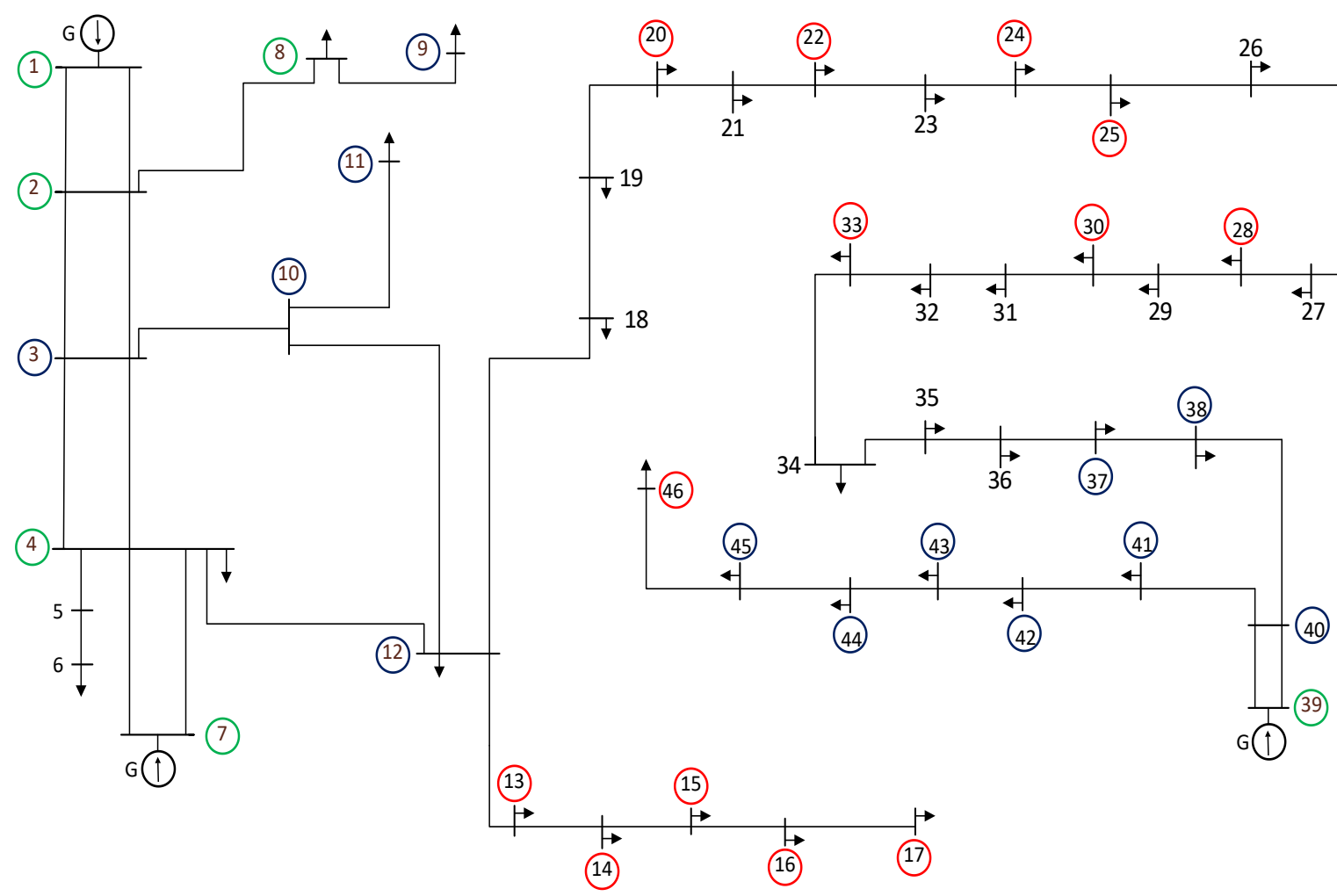

Figure 2. GBAO radial circuit

The circuit consists of 46 nodes and with calculation of the normal mode is divided into the nodes classes of the following voltage level: low, below normal, normal, normal high, and high. Voltage nodes (linguistic variable nodes (low voltage)) are marked with a red color. These nodes are: 13, 14, 15, 16, 17, 20, $22,24,25,28,30,33,41,46$. Total nodes are 14 . The Table 1 shows the nodes voltage obtained as a result of the normal mode calculations made in the distribution electrical network using RastrWin3 software package (SP).

RastrWin3 software package (SP) is designed to solve problems related to the calculation, analysis and modes optimization in electrical networks and systems. The original modification of the full Newton method with optimal step selection was developed in the software used for calculating EPS modes set, taking into account equation peculiarities of nodes voltage given in the rectangular coordinates. The nodes of appropriate linguistic variable with voltage "below normal" is circled with a blue color and these nodes are: $3,4,9,10,11,12,37,38,40,42,43,44$. Total nodes are 12 . 
Table 1. Voltage value in nodes of the GBAO electric network model

\begin{tabular}{|c|c|c|c|c|c|c|c|}
\hline Type & Number & Name & $P_{n, \mathrm{MW}}$ & $Q_{n}, \mathrm{MVAr}$ & $P_{g}, \mathrm{MW}$ & $Q_{g}, \mathrm{MVAr}$ & $U, \mathrm{kV}$ \\
\hline Base & 1 & Pamir 1 & & & 13.3 & 3.0 & 6.60 \\
\hline Load & 2 & 1 & & & & & 34.93 \\
\hline Load & 3 & 2 & & & & & 33.49 \\
\hline Load & 4 & 3 & 2.7 & 0.9 & & & 33.49 \\
\hline Load & 5 & 4 & & & & & 33.05 \\
\hline Load & 6 & Roshtkala & 1.7 & 0.6 & & & 32.27 \\
\hline Load & 7 & Khorog & & & 9.0 & 6.6 & 6.30 \\
\hline Load & 8 & Navobod & 0.8 & 0.3 & & & 34.54 \\
\hline Load & 9 & Vid & 1.0 & 0.3 & & & 34.06 \\
\hline Load & 10 & Branch line & & & & & 33.16 \\
\hline Load & 11 & Jomi & 1.0 & 0.3 & & & 33.11 \\
\hline Load & 12 & Bizmich & 5.2 & 1.7 & & & 32.96 \\
\hline Load & 13 & Pornishev & 1.5 & 0.6 & & & 31.27 \\
\hline Load & 14 & Buni & 0.4 & 0.1 & & & 30.57 \\
\hline Load & 15 & Pastbaju & 0.1 & 0.0 & & & 29.54 \\
\hline Load & 16 & Pastkhuf & 0.3 & 0.1 & & & 29.22 \\
\hline Load & 17 & Rushan & 2.1 & 1.1 & & & 28.52 \\
\hline Load & 18 & 5 & 0,1 & 0,0 & & & 32,25 \\
\hline Load & 19 & Virujak & 0.8 & 0.5 & & & 32.10 \\
\hline Load & 20 & Gojak & 0.6 & 0.4 & & & 31.92 \\
\hline Load & 21 & Pish & 0.5 & 0.2 & & & 31.70 \\
\hline Load & 22 & Nishusp & 0.2 & 0.1 & & & 31.46 \\
\hline Load & 23 & Andarob & 0.3 & 0.1 & & & 31.19 \\
\hline Load & 24 & Qal'ailal & 0.6 & 0.4 & & & 31.05 \\
\hline Load & 25 & Expedition & 1.3 & 0.7 & & & 31.04 \\
\hline Load & 26 & Sist & 0.1 & 0.0 & & & 31.16 \\
\hline Load & 27 & Vogz & 0.0 & 0.0 & & & 31.20 \\
\hline Load & 28 & Shanbedeh & 0.1 & 0.0 & & & 31.26 \\
\hline Load & 29 & Bagush & 0.0 & 0.0 & & & 31.51 \\
\hline Load & 30 & Qozideh & 0.1 & 0.0 & & & 31.73 \\
\hline Load & 31 & Barshor & 0.0 & 0.0 & & & 31.77 \\
\hline Load & 32 & Avj & 0.0 & 0.0 & & & 31.89 \\
\hline Load & 33 & Mulvog & 0.1 & 0.0 & & & 32.01 \\
\hline Load & 34 & Yakhshvol & 0.0 & 0.0 & & & 32.08 \\
\hline Load & 35 & Sumchin & 0.0 & 0.0 & & & 32.18 \\
\hline Load & 36 & Tamoznnya & 0.0 & 0.0 & & & 32.44 \\
\hline Load & 37 & Ishkoshim & 0.7 & 0.2 & & & 32.56 \\
\hline Load & 38 & Namadgud & 0.2 & 0.1 & & & 33.14 \\
\hline Load & 39 & Ishkoshim HPP & & & 2.5 & 2.1 & 6.30 \\
\hline Load & 40 & 6 & & & & & 33.23 \\
\hline Load & 41 & Darshay & 0.0 & 0.0 & & & 32.87 \\
\hline Load & 42 & Shitkharv & 0.1 & 0.0 & & & 32.73 \\
\hline Load & 43 & Zumudg & 0.0 & 0.0 & & & 32.56 \\
\hline Load & 44 & Navobod & 0.0 & 0.0 & & & 32.47 \\
\hline Load & 45 & Pitup & 0.3 & 0.1 & & & 32.43 \\
\hline Load & 46 & Vrang & 0.3 & 0.1 & & & 32.33 \\
\hline
\end{tabular}

The nodes complying with linguistic variable with voltage "normal" is circled with a green color (nodes: 1, 2, 7, 8, 39). The number of nodes is 5 . If voltage classes are "above normal" and "high", the nodes are missing. The following range of functions was taken:

- «Normal» $34.5 \leq X<35.5 \mathrm{kV}$,

- «Below normal» $32.5 \leq X<34.5 \mathrm{kV}$,

- «Low» $28 \leq X<32.5 \mathrm{kV}$.

Membership functions are given in the Figure 3. Likewise, the fuzzy classification of active power loss index in the network was provided and was separated into classes using linguistic variables of power loss: low, below, average, above average, and high that are shown in Figure 4.

To determine the location priority of CD installation, the linguistic matrix of fuzzy relationship was used between two such fuzzy variables as a voltage and power loss. Linguistic matrix was given in Table 2. Based on the parameters of normal mode as shown in Table 1 and fuzzy relationship matrix given in Table 2 , there will be 13 main nodes for the CD to be installed. The nodes priority is defined by their relation towards the low voltage class and below average voltage [24]-[26]. The power selection for CDs in the nodes was marked for the purpose of their location and implemented with swarm intelligence algorithm-using fire-fly method. 


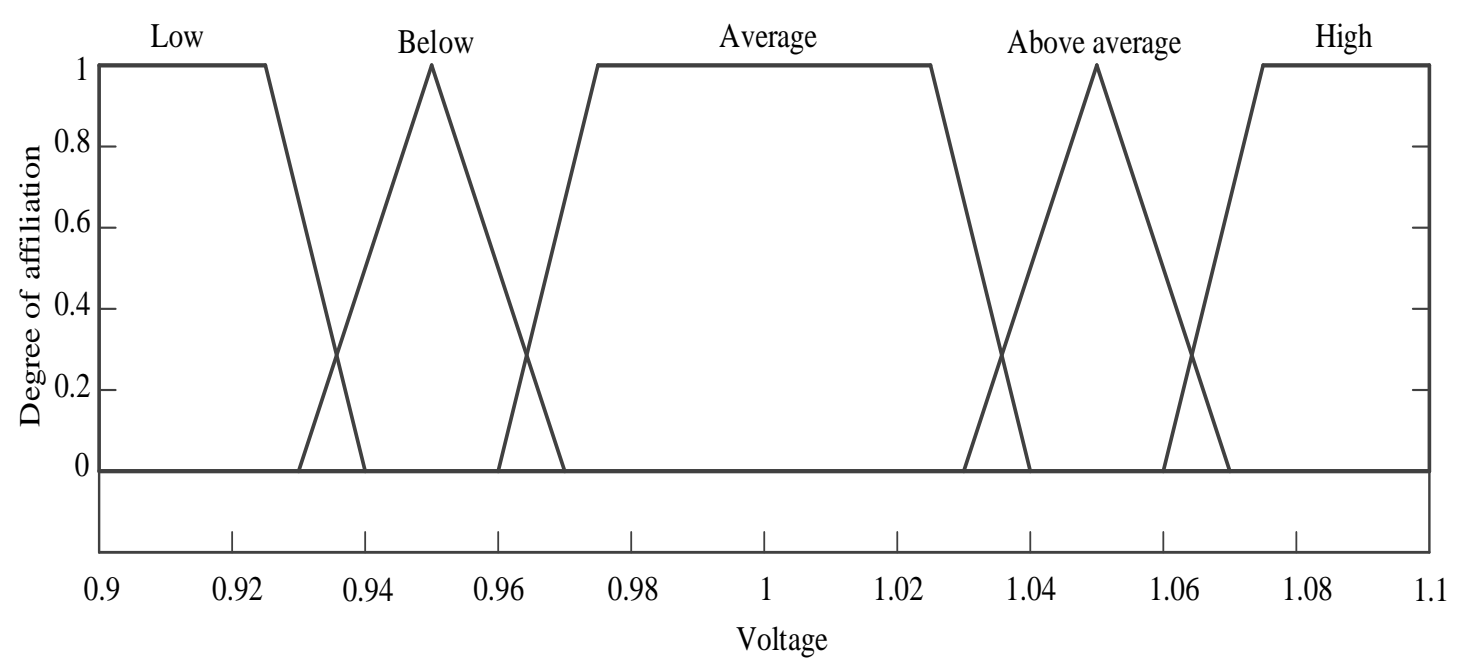

Figure 3. Membership function for the voltage in the node

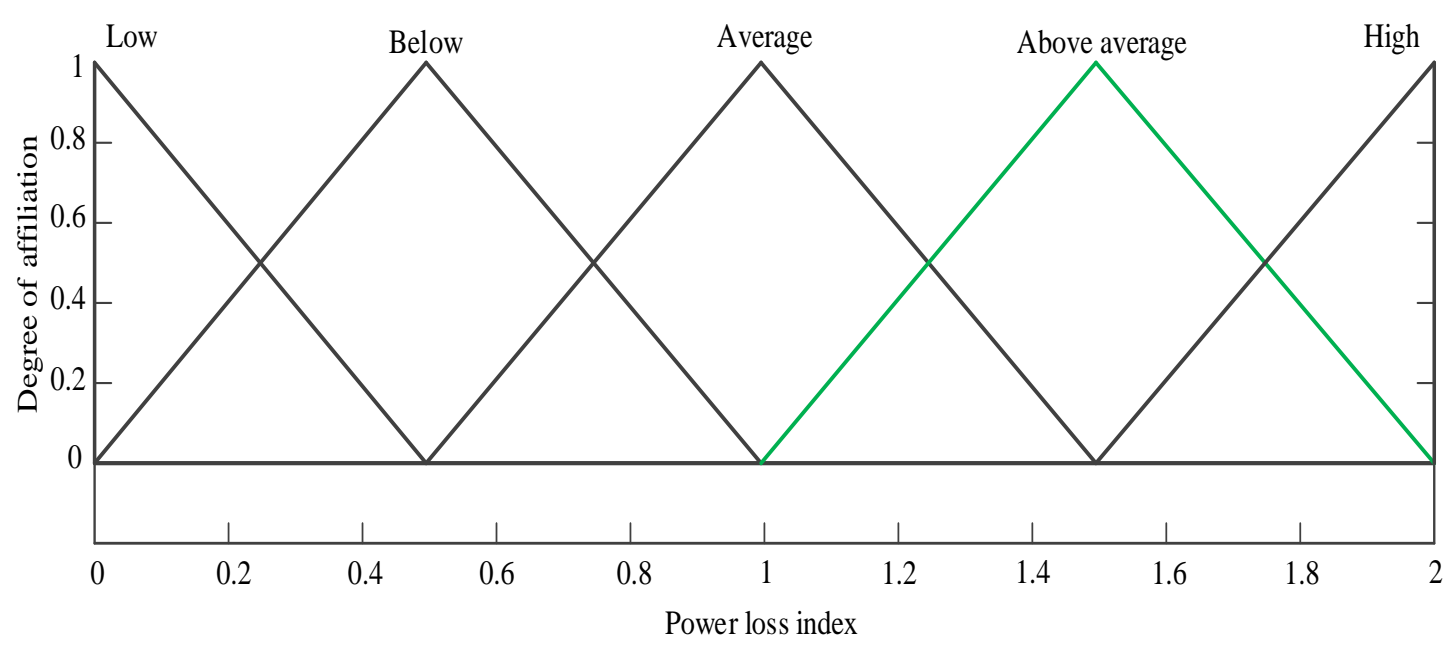

Figure 4. Membership function of power loss index in the branches

Table 2. Linguistic matrix of CD location feasibility

\begin{tabular}{|c|c|c|c|c|c|c|}
\hline \multirow{2}{*}{\multicolumn{2}{|c|}{$\Delta \mathrm{P}$}} & \multicolumn{5}{|c|}{ VoltageU } \\
\hline & & Low & Below normal & Normal & Above normal & High \\
\hline \multirow{5}{*}{ 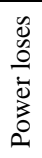 } & Low & below & below & low & low & low \\
\hline & Below & average & below & below & low & low \\
\hline & Average & aboveaverage & average & below & low & low \\
\hline & Aboveaverage & aboveaverage & aboveaverage & average & below & low \\
\hline & High & high & aboveaverage & average & below & below \\
\hline
\end{tabular}

\section{CD LOCATION OPTIMIZATION USING FIRE-FLY ALGORITHM}

Mathematical statement of optimization problem is active power loss minimization, CD costs minimization and $\tan (\varphi)$ value ensuring that must be no more than 0.35 . The simplest way to reduce multiobjective problems to a single-objective one is a linear convolution. Active power loss and cost of CDs can be combined into a single-objective of financial loss, taking into consideration per unit cost of power loss $(1 \mathrm{~kW})$ and per unit of CDs power (kVAr). The price of $c_{p}$ power loss is defined by the tariff used by the consumers. $\tan (\varphi)$ value was a criterion and transformed into the limitations. In addition, $\tan (\varphi)$ value was limited from below because the low value $\tan (\varphi)$ can result in a system stability loss [26]-[30]. Mathematical problem formulation of a single-objective optimization is defined as (1), (2), (3): 


$$
\begin{aligned}
& W(Q)=C(Q)+E_{\Delta P}(Q) \rightarrow \min \\
& Q=\left\{\begin{array}{c}
\left.Q_{1}, Q_{2}, Q_{3}, \ldots, Q_{n}\right\} \\
E_{\Delta P}=c_{p} \tau \Delta P
\end{array}\right\} \\
& C(Q)=c_{c u} \sum_{i=1}^{n} Q_{i}
\end{aligned}
$$

Under constraints

$$
Q_{\min i}<Q_{i}<Q_{\max i}
$$

where $i$-is the current index of the reactive power source,

$$
\begin{aligned}
& 0<Q_{k i}<Q_{i}, \quad i=1,2,3, \ldots, n \\
& 0.1<\tan (\varphi)<0.35
\end{aligned}
$$

where $C(Q)$ - is a capital cost for CD installation; $E_{\Delta P}-$ is a value of active power loss; $Q_{k}-$ is a CD power vector; $Q_{i}$ - is a CD power in $i$-node (if $Q_{\max i}=0, \mathrm{CD}$ installation is not required in $i$-node); $n$-is a number of nodes which CD can be installed for the considered section of such nodes are $14 ; \tau-$ is a number of hours of maximum loss; $\Delta P$ - is a total loss of active power in the network; $Q_{\max i}-$ is a maximum installed capacity of CD in $i$-node. As a result of optimization problem solution the optimal CDs power in the selected priority nodes are determined and summarized in the Table 3. As CDs have discreteness regulated by parameters and power discreteness of the produces electrical equipment, some values in Table 3 of the article are rounded up to the nominal values.

Table 3. CD Power in the priority nodes

\begin{tabular}{cccc}
\hline Node number & $\begin{array}{c}\text { Compensating device } \\
\text { power, MVAr }\end{array}$ & Node number & $\begin{array}{c}\text { Compensating device } \\
\text { power, MVAr }\end{array}$ \\
\hline 12 & 1.511 & 12 & 1.500 \\
13 & 0.517 & 13 & 0.500 \\
14 & 0.01 & 14 & 0 \\
15 & 0.03 & 15 & 0 \\
16 & 0.08 & 16 & 0.100 \\
17 & 1.014 & 17 & 1.000 \\
20 & 0 & 20 & 0 \\
24 & 0.03 & 24 & 0 \\
25 & 0.592 & 25 & 0.600 \\
28 & 0.02 & 28 & 0 \\
30 & 0 & 30 & 0 \\
33 & 0 & 33 & 0 \\
41 & 0.01 & 41 & 0 \\
46 & 0.01 & 46 & 0 \\
\hline
\end{tabular}

\section{CONCLUSION}

A new approach, towards the selection of CDs location in the electrical networks based on fuzzy relationship matrix linking voltage level in the nodes, power loss in the branches and power factor of the network, is suggested. Priority selection is carried out for the network nodes with low voltage and voltage below normal and, correspondingly, with high loss. The calculations conducted confirmed the correctness of the selection model suggested.

Optimal distribution of the reactive power sources in the distribution networks of GBAO is conducted on the basis of swarm intelligence algorithms; in particular, fire-fly algorithm while searching minimum target function covers entire area of possible solutions compared to widely-used gradient method. A fire-fly method is suggested and tested enabling to solve a problem using two objectives with a possibility of global minimum search. It should be noted that the algorithm can find the area of the global extremum, but not the extremum itself, due to its diversification property, which allows it not to "get stuck" in local areas. 
For a more accurate solution of the problem, the firefly method can be used and before optimization, by the gradient method, which is the task of subsequent scientific works.

\section{ACKNOWLEDGEMENTS}

The reported study was funded by RFBR, project number 19-38-90204.

\section{REFERENCES}

[1] C. H. S. Akhyoyev, A. K. Kirgizov, and E. G. Yadagayev, "A fuzzy model of distributed generation of renewable energy in the Republic of Tajikistan," Science Bulletin of the NSTU, vol. 64, no. 3, pp. 117-130, 2016, doi: 10.17212/1814-1196-2016-3-117-130.

[2] S. E. Kokin et al., "Features of the management of hydroelectric power in the power system of the Republic of Tajikistan," News of the Scientific and Technical Center of the Unified Energy System, vol. 77, no. 2, pp. 109-118, 2017.

[3] V. Manusov, A. Kirgizov, and J. Ahyoev, "Construction and optimization of a power complex with a distributed generation on the basis of renewable and methods of artificial intelligence (on the example of the Republic of Tajikistan)," in E3S Web of Conferences, vol. 6, 2016, Art. no. 03006, doi: 10.1051/e3sconf/20160603006.

[4] M. A. Golkar, "Reactive power control in distribution systems by using advanced techniques," in Proceedings of the 2011 3rd International Youth Conference on Energetics (IYCE), 2011, pp. 1-6.

[5] T. F. Lee et al., "Optimization of Reactive Power Compensation and Voltage Regulation Using Artificial Immune Algorithm for Radial Transmission Networks," International journal of engineering intelligent systems for electrical engineering and communications, vol. 15, no. 2, pp. 1-6, 2007, doi: 10.1109/ISAP.2007.4441689.

[6] J. Klucznik, K. Dobrzyński, and Z. Lubośny, "Voltage and Reactive Power Load Flow Optimization in the Power System Using Fuzzy Logic," Acta Energetica, vol. 13, no. 1, pp. 56-62, 2013, doi: 10.12736/issn.2300-3022.2013105.

[7] M. T. Ameli, V. Shokri, and S. Shokri, "Using Fuzzy Logic \& Full Search for Distributed generation allocation to reduce losses and improve voltage profile," in Proceedings of the 2010 International Conference on Computer Information Systems and Industrial Management Applications (CISIM), pp. 626-630, 2010, doi: 10.1109/CISIM.2010.5643526.

[8] N. Gupta, S. P. Singh, and S. P. Dubey, "Fuzzy logic controlled shunt active power filter for reactive power compensation and harmonic elimination," in Proceedings of the 2011 2nd International Conference on Computer and Communication Technology (ICCCT), 2011, pp. 82-87, doi: 10.1109/ICCCT.2011.6075180.

[9] T. Moger, and T. Dhadbanjan, "Fuzzy Logic Approach for Reactive Power Coordination in Grid Connected Wind Farms to Improve Steady State Voltage Stability," IET Renewable Power Generation, vol. 11, no. 2, pp. 351-361, 2016, doi: 10.1049/iet-rpg.2016.0119.

[10] C. Ramesha, M. Rajaramb, and S. C. Pandian, "Fuzzy Logic Implementation for Reactive Power Control in Utility System," International Review of Electrical Engineering, vol. 7, no. 4, pp. 5036-5042, 2012.

[11] D. Xie, J. X. Gong, J. S. Xu, and Y. C. Zhang, "A new Var optimal compensation strategy based on data mining and ant colony algorithm," Power System Protection and Control, vol. 37, no. 10, pp. 19-26, 2009.

[12] N. K. Sharma, D. S. Babu, and S. C. Choube, "Application of particle swarm optimization technique for reactive power optimization," in Proceedings of the International Conference on Advances in Engineering, Science and Management (ICAESM), 2012, pp. 88-93.

[13] P. Subbaraj, and P. N. Rajnarayanan, "Hybrid Particle Swarm Optimization Based Optimal Reactive Power Dispatch," International Journal of Computer Applications, vol. 1, no. 5, pp. 65-70, 2010, doi: 10.5120/121-236.

[14] A. P. Karpenko, "Modern search engine optimization algorithms. Algorithms inspired by nature," A training manual, Publishing House MSTU. N.E. Bauman, Moscow, 2014.

[15] G. Koeppel, "Reliability considerations of future energy systems: Multicarrier systems and the effect of energy storage,” Diss. ETH No. 17058, EidgenössischeTechnische Hochschule Zürich, 2007.

[16] M. Braae and D. A. Rutherford, "Selection of parameters for fuzzy logic controller," Fuzzy Sets and Systems, vol. 3, pp. 185-199, 1979.

[17] U. Bumtsend, M. Safaraliev, A. Ghulomzoda, B. Ghoziev, J. Ahyoev, and G. Ghulomabdolov, "The Unbalanced Modes Analyze Of Traction Loads Network," in Ural Symposium on Biomedical Engineering, Radioelectronics and Information Technology (USBEREIT), 2020, pp. 0456-0459, doi: 10.1109/USBEREIT48449.2020.9117758.

[18] U. Mukherjee, A. Maroufmashat, J. Ranisau, M. Barbouti, and A. Trainor, "Techno-economic, environmental, and safety assessment of hydrogen powered community microgrids; case study in Canada," International Journal of Hydrogen Energy, vol. 42, pp. 14333-14349, 2017, doi: 10.1016 / j.ijhydene.2017.03.083.

[19] H. R. Baghaee, M. Mirsalim, and G. B. Gharehpetian, "Multi-objective optimal power management and sizing of a reliable wind/PV microgrid with hydrogen energy storage using MOPSO," Journal of Intelligent \& Fuzzy Systems, vol. 32, no. 3, pp. 1753-1773, 2017, doi: 10.3233/JIFS-152372.

[20] F. Cell, and H. J. Undertaking, "Study on Early Business Cases for H2 in Energy Storage and More Broadly Power to $\mathrm{H} 2$ Applications," FCH-JU, Brussels, Belgium, 2017.

[21] P. Rocca, M. Benedetti, M. Donelli, D. Franceschini, and A. Massa, "Overview of evolutionary optimization techniques based on swarm intelligence," News of the Southern Federal University, vol. 113, no. 12, pp. 7-12, 2010 .

Expert system application for reactive power compensation in isolated electric power... (A. K. Kirgizov) 
[22] K. M. Passino, "Biomimicry of bacterial foraging for distributed optimization and control," IEEE Control Systems Magazine, vol. 22, no. 3, pp. 52-67, 2002, doi: 10.1109/MCS.2002.1004010.

[23] D. T. Pham, A. Ghanbarzadeh, E. Koç, S. Otri, S. Rahim, and M. Zaidi, "The Bees Algorithm-a Novel Tool for Complex Optimisation Problems," in Proceedings of IPROMS 2006 Conference, 2006, pp. 454-459, doi: 10.1016/B978-008045157-2/50081-X.

[24] P. V. Matrenin et al., "Adaptive Particle Swarm Optimization for the Operational Scheduling Problem," Bulletin of computer and information technology, vol. 142, no. 4, pp. 11-15, 2016.

[25] E. F. Keller, "Organisms, Machines, and Thunderstorms: A History of Self-Organization, Part Two. Complexity, Emergence, and Stable Attractors," Historical Studies in the Natural Sciences, vol. 39, no. 1, pp. 1-31, 2009, doi: 10.1525/hsns.2009.39.1.1.

[26] G. K. Jati., "Evolutionary discrete firefly algorithm for travelling salesman problem," in Proceedings of the Second international conference on Adaptive and intelligent systems (ICAIS'11), Springer-Verlag, Berlin, Heidelberg, 2011, pp. 393-403.

[27] D. Karaboga, “An Idea Based on Honey Bee Swarm for Numerical Optimization,” Erciyes University, Technical Report, 2005.

[28] S. A. Kazemzadeh, "Optimum design of structures using an improved firefly algorithm," International Journal of Optimization in Civil Engineering, vol. 1, no. 2, pp. 327-340, 2011.

[29] A. R. Yildiz, "Cuckoo search algorithm for the selection of optimal machining parameters in milling operations," The International Journal of Advanced Manufacturing Technology, vol. 64, pp. 1-4, 2012, doi: 10.1007/s00170012-4013-7.

[30] D. H. Wolpert, and W. G. Macready, "No free lunch theorems for optimization," IEEE Transaction on Evolutionary Computation, vol. 1, no. 1, pp. 67-82, 1997.

\section{BIOGRAPHIES OF AUTHORS}

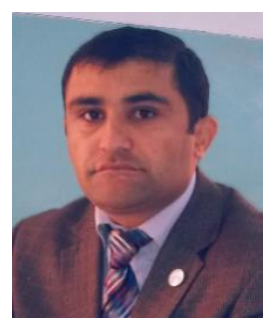

Alifbek K. Kirgizov Tajik Technical University named after academic M. S. Osimi, Department of Electric Power Stations, Ph.D., Associate Professor. Main directions of investigations: methods of artificial intelligence for planning and optimization of operating regimes of power systems. E-mail: alifbek@mail.ru

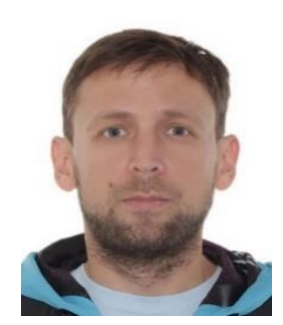

Stepan A. Dmitriev Ural Federal University named after the first President of Russia B.N. Yeltsin, Department of Automated Electrical Systems, Ph.D., Associate Professor. Main directions of investigations: monitoring and diagnostics of current technical condition of high voltage electrical equipment on the basis of the theory of fuzzy sets and fuzzy logic. E-mail: dmstepan@gmail.com

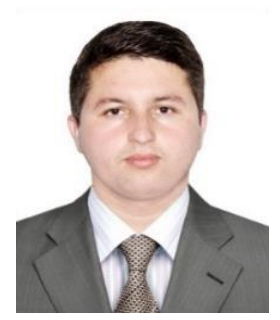

Murodbek Kh. Safaraliev Ural Federal University named after the first President of Russia B.N. Yeltsin, Department of Automated Electrical Systems, postgraduate student. Main directions of investigations: optimization of the development and control of modes ofelectrical systems, electric stations and isolated electrical power systems. E-mail: murodbek_03@mail.ru

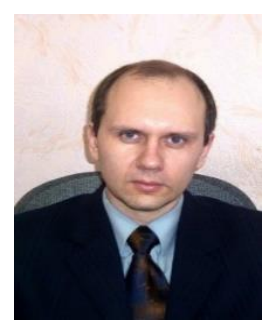

Dmitry A. Pavlyuchenko Novosibirsk State Technical University, Department of Power Supply Systems, Ph.D., Associate Professor, Head of Department. Main directions of investigations: enhancement of energy efficiency, operating performance and development of power supply systems. E-mail: pavlyuchenko@ copr.nstu.ru 


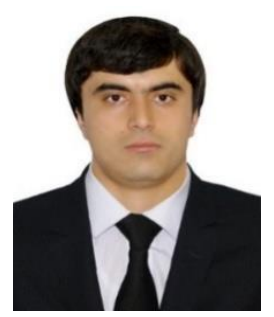

Anvari H. Ghulomzoda Novosibirsk State Technical University, Department of Automated Electric Power Systems, postgraduate student. Main directions of investigations: electrical equipment of power stations and substations, automation of power systems, stability of power stations and power systems. E-mail: anvar_4301@mail.ru

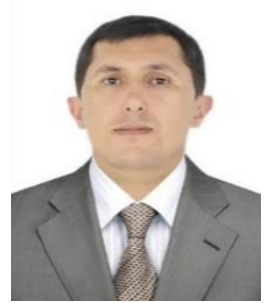

Javod S. Ahyoev Tajik Technical University named after academic M. S. Osimi, Department of Electric Power Stations, Ph.D., Associate Professor. Main directions of investigations: monitoring and diagnostics of current technical condition of high voltage electrical equipment on the basis of the theory of fuzzy sets and fuzzy logic. E-mail: javod_66@mail.ru 